\title{
COGNITIVE FUNCTION IN WORKING POPULATION WITH ABNORMAL THYROID FUNCTION TEST"
}

\author{
Dr. Nilanjana \\ Debnath \\ Dr. Keshao B. \\ Nagpure*

\section{Dr. Preetam N.} \\ Wasnik
} (MBBS), Intern, All India Institute of Medical Sciences (AIIMS), Raipur (Chhattisgorh).

(MD), Assistant professor, Department of General Medicine, AIIMS Raipur. ${ }^{*}$ Corresponding Author

(MD),Associate professor, Department of General Medicine, AIIMS Raipur .

ABSTRACT Context: Cognitive impairment is linked to thyroid dysfunction in various studies; however, the evidence is mixed. Aims: To determine cognitive function in the working population with abnormal thyroid function tests. Settings: Outpatient department of Medicine in a tertiary care hospital located in Central India. Design: Hospital-based, cross-sectional study. Methods and Material:100 patients between 15-64 years of age with different patterns of thyroid dysfunction were subjected to cognitive function testing via the Mini-Mental Status Examination (MMSE) questionnaire. Statistical analysis used: The data obtained was coded in a Microsoft Excel Worksheet and analyzed by SPSS software version 21. Results: 100 patients ( $11 \%$ men and $89 \%$ women) were included in the present study. The mean age of the study population was $37.11 \pm 8.76$ years. $87 \%$ had overt hypothyroidism, $6 \%$ had subclinical hypothyroidism, $6 \%$ had overt hyperthyroidism. The mean MMSE score of patients with abnormal thyroid function tests was $27.62 \pm 2.04$ (Range 23-30). The mean MMSE score in patients with overt hypothyroidism was $27.54 \pm 2.07$, that of overt hyperthyroidism $28.33 \pm 1.03$, and that of subclinical hypothyroidism was $27.67 \pm 2.50$. MMSE scores among different patterns of thyroid dysfunction were not found to be statistically significant. The MMSE scores between newly and previously diagnosed patients with thyroid dysfunction were not statistically significant. $(28.3 \pm 1.06$ vs $27.54 \pm 2.12)$. Conclusions: The results suggest no association between cognitive function and abnormal thyroid function tests in the working population.

\section{KEYWORDS : cognitive function, thyroid dysfunction, hypothyroidism, hyperthyroidism}

INTRODUCTION:

The thyroid hormone regulates metabolic processes that are essential for normal growth and development as well as neurocognitive functioning after development. ${ }^{[1]}$ Cognition is defined as the mental action or process of acquiring knowledge and understanding through thought, experience, and the senses. Different types of screening tests for cognitive function assessment have been used in clinical medicine as well as for research purposes ${ }^{[2]}$. The Folstein mini-mental status examination (MMSE) is a standardized screening examination of cognitive function that is extremely easy to administer and takes $<10$ minutes to complete. Individual elements of the mental status examination can be subdivided into level of consciousness, orientation, speech and language, memory, fund of information, insight, and judgment, abstract thought, and calculations. ${ }^{[3]}$ It is well known that hypothyroidism affects cognition as seen in Cretinism, which refers to hypothyroidism seen in infancy or childhood. However, low thyroid function is believed to cause deterioration of cognition at any age as it can prevent the brain from adequate sustenance of energy-consuming processes that are involved in neurotransmission, memory, and other higher functions. ${ }^{[4]}$ Hyperthyroid patients are also found to show a variety of cognitive function deficits, though, to a lesser degree than that of hypothyroid patients, common cognitive function deficits being seen in the hyperthyroid patients included poorer performances on tests of attention, memory, and mental alertness. ${ }^{[5,6]}$ Some studies show a negative association between abnormal thyroid function tests and cognitive dysfunction. ${ }^{[7-10]} \mathrm{A}$ concrete link between thyroid function and cognition is yet to be arrived at, with many studies attempting at the same, this study included.

There are available many studies that look into thyroid function as a factor that can contribute to cognitive functioning, especially in the elderly. ${ }^{[7-9]}$ An intact cognitive function is an essential requirement for determining one's productivity at the workplace. A study showed that impaired cognition has been associated with the occurrence of injuries in industrial workers. ${ }^{[1]}$ There is also the growing recognition that poor mental health is a crucial factor in the development of physical illnesses, that may affect one's productivity. Therefore, the present study aimed to determine cognitive function in the working population (individuals 15 to 64years) with an abnormal thyroid function test.

\section{Subjects and Methods:}

A total of 100 patients were recruited in this hospital-based, cross-sectional study of 2 months duration. Those recruited in the study were previously or newly diagnosed patients of thyroid dysfunction aged 15-64 years attending the outpatient department of the tertiary care institute meeting the eligibility criteria. The power of the study was calculated at $83.4 \%$, using G- power software. The exclusion criteria for the study included a history of other possible causes of cognitive impairment, namely diabetes, hypertension, and other cardiovascular diseases, cerebrovascular accidents, head injury, neurological or neurodegenerative disease, history of drug intake (Benzodiazepines, anticholinergics, etc.), smoking, alcohol intake, and Vit Bl2 deficiency. The 100 selected patients were then subjected to a Mini-Mental Status Examination (MMSE) questionnaire to assess cognition. Scores below 24 were considered to have cognitive impairment (18-23: mild, <18: severe).

Statistical Analysis: The data were coded in a Microsoft Excel Worksheet and tables, charts were prepared. Data analysis was done by SPSS software version 21. Shapiro's test is used to check whether data is normally distributed or not. Data were analyzed as per normality. The categorical variables were expressed as percentages, frequency, and proportions and compared using Pearson's chi-square test or Fisher's exact test, as appropriate. The quantitative data were expressed as mean \pm standard deviation (SD) and compared using independent sample t-test or Mann-Whitney U test. More than two means were compared using one-way ANOVA or 
Kruskal- Wallis test. Statistical test results with P-value $(\mathrm{P})<$ 0.05 will be considered statistically significant.

\section{Results:}

Of the 100 patients recruited in the study, there were $11 \%$ men and $89 \%$ women. The majority of the patients $(41 \%)$ were of the age category of $36-45$ years with the next largest group of patients in the age group of $26-35$ years (36\%). The mean age of the men recruited in the study was found to be of $42 \pm 8.95$ years, that of women was $36.49 \pm 9.52$ years, and the mean age of the entire population was $37.11 \pm 8.76$ years.

$87(87 \%)$ patients were of overt hypothyroidism, (9 male and 78 females),6 ( $6 \%$ )of subclinical hypothyroidism ( 2 males and 4 females), and 6 (6\%) of overt hyperthyroidism, all of whom were female. 1 (\%) patient was categorized as "others", owing to having an elevated T4 as well as TSH level (secondary hyperthyroidism). Most patients (90\%) were previously diagnosed as having thyroid dysfunction and $10 \%$ were newly diagnosed. Of the 10 newly diagnosed patients, 3 of them were diagnosed as being overtly hypothyroid, 6 with subclinical hypothyroidism (see Figure 1).

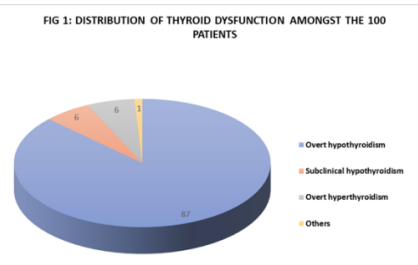

Of the 90 previously diagnosed patients, a majority, i.e. 84 (93.34\%) patients were known to be overtly hypothyroid, and the remaining $6(6.66 \%)$ were known to be having overt hyperthyroidism. There were no cases of subclinical hyperthyroidism and all cases of subclinical hypothyroidism were newly diagnosed.

The mean MMSE score of patients with abnormal thyroid function tests was $27.62 \pm 2.04$ (Range 23-30). The mean MMSE score in patients with overt hypothyroidism was 27.54 \pm 2.07 that of overt hyperthyroidism $28.33 \pm 1.03$ and that of subclinical hypothyroidism was $27.67 \pm 2.50$. The difference in MMSE scores among different patterns of abnormal thyroid function test was not found to be statistically significant. (P $>0.05$ ) (see tables 1 and 2). Also, it was found that of the 87 overt hypothyroid patients, 79 (90.8\%) had normal cognitive function while there was mild cognitive impairment in the remaining $8(9.2 \%)$, out of the 6 subclinical hypothyroid patients, all had normal cognitive function while of the 6 that had overt hyperthyroidism, l was found to have mild impairment of cognition while the rest were having a normal cognitive function.

Table 1: Mean MMSE Scores in Patients with Different Patterns of Thyroid Dysfunction

\begin{tabular}{|c|c|c|c|c|c|}
\hline Pattern & $\begin{array}{c}\text { Overt } \\
\text { Hypothyr } \\
\text { oidism }\end{array}$ & $\begin{array}{c}\text { Subclinic } \\
\text { al } \\
\text { Hypothyr } \\
\text { oidism }\end{array}$ & $\begin{array}{c}\text { Overt } \\
\text { Hyperthyr } \\
\text { oidism }\end{array}$ & $\begin{array}{c}\text { Subclinical } \\
\text { Hyperthyroid } \\
\text { ism }\end{array}$ & \\
\hline $\begin{array}{c}\text { Mean } \\
\text { MMSE }\end{array}$ & $\begin{array}{c}27.54 \pm 2 . \\
\text { Score }\end{array}$ & $\begin{array}{c}27.67 \pm 2 . \\
50\end{array}$ & $\begin{array}{c}28.34 \pm 1.0 \\
3\end{array}$ & - & $\mathrm{p}>0.0$ \\
5
\end{tabular}

Table 2: Degree of Cognitive Impairment in Patients with Different Patterns of Thyroid Dysfunction

\begin{tabular}{|c|c|c|c|c|c|}
\hline Pattern & Overt & Subclinical & Overt & Subclinical & Othe \\
& Hypothyroi & Hypothyroi & Hyperthyr & Hyperthyroi & rs \\
dism & dism & oidism & dism & $(\mathrm{N}=1$ \\
& $(\mathrm{N}=87)$ & $(\mathrm{N}=6)$ & $(\mathrm{N}=6)$ & & ) \\
\hline
\end{tabular}

\begin{tabular}{|c|c|c|c|c|c|}
\hline $\begin{array}{c}\text { No } \\
\text { Cognitive } \\
\text { Impairment }\end{array}$ & $\begin{array}{c}78 \\
(89.65 \%)\end{array}$ & 6 & 5 & 0 & 1 \\
\hline $\begin{array}{c}\text { Mild } \\
\text { Cognitive } \\
\text { Impairment }\end{array}$ & $\begin{array}{c}9(10.35 \% \\
)\end{array}$ & 0 & 1 & 0 & 0 \\
\hline
\end{tabular}

There was no significant difference in MMSE scores between normal and abnormal TSH (out of range) as well as between normal and abnormal FT4 ( $p>0.05$ ) (see Table 3).

Table 3: MMSE Scores in Patients with Normal and Abnormal Free T4 and TSH

\begin{tabular}{|c|c|c|c|c|}
\hline & $\begin{array}{c}\text { Free T4 } \\
(\mathrm{N}=100)\end{array}$ & MMSE & TSH & MMSE \\
\hline $\begin{array}{c}\text { Normal } \\
\text { Range }\end{array}$ & $68(\%)$ & $27.6 \pm 2.06$ & $34(\%)$ & $27.58 \pm 2.06$ \\
\hline $\begin{array}{c}\text { Less Than } \\
\text { Normal }\end{array}$ & $22(\%)$ & $27.55 \pm 2.1$ & $16(\%)$ & $27.49 \pm 2.06$ \\
\hline $\begin{array}{c}\text { More Than } \\
\text { Normal }\end{array}$ & $10(\%)$ & $27.6 \pm 2.05$ & $50(\%)$ & $27.6 \pm 2.06$ \\
\hline $\begin{array}{c}\text { Total } \\
\text { Abnormal } \\
\text { (Out of } \\
\text { Range) }\end{array}$ & $32(\%)$ & & $66(\%)$ & \\
\hline
\end{tabular}

The mean MMSE scores of those previously diagnosed (and hence currently receiving treatment) were found to be $27.54 \pm$ 2.12 and those of newly diagnosed (and hence treatment naive) were found to be $28.3 \pm 1.06$ with the difference found to be insignificant $(p>0.05)$. Owing to a skewed distribution of the subjects within the 4 categories of thyroid dysfunction, logistic regression to find independent predictors couldn't be performed.

\section{DISCUSSION:}

Cognitive function has been studied in various studies to date, showing positive as well as negative associations between specific patterns of abnormal thyroid function tests. ${ }^{[5-16]}$ In most studies, cognitive function was studied in the elderly population with thyroid dysfunction. ${ }^{[7-10,12,16]}$ A communitybased Italian study was done on the same aspect on a population between 23-102 years of age, ${ }^{[5]}$ while a recent hospital-based case-control Indian study was done on a population between $18-60$ years of age. ${ }^{[15]}$ The present study included all patients with abnormal thyroid function tests between 15-64 years of age, i.e. the working population, as cognition is an important domain in this group of population. Most of the patients in the present study were females (89\%), as compared to other studies where the proportion of females was between $60-70 \% .^{[5,15-16]}$

Most of the studies on cognitive function in thyroid disorder were conducted on patients with clinical and subclinical hypothyroidism ${ }^{[13-14,16]}$ and few on clinical and subclinical hyperthyroidism. ${ }^{[6,14]}$ The present study included patients with different patterns of clinical as well as subclinical thyroid disease.

All the patients in the study who were previously diagnosed were on treatment. K.J. Miller et.al. reported memory improvement after treatment in hypothyroid patients, ${ }^{[18]}$ which provides a rationale for normal cognitive function in most patients with thyroid dysfunction in the present study.

MMSE scores between patients with normal and abnormal FT4 as well as patients with normal and abnormal TSH were comparable. These results were found to be on similar lines to some of the previously conducted studies. ${ }^{[8,16]}$ Forti P. et.al., reported no association between baseline TSH and the risk of developing cognitive impairment. ${ }^{[10]}$ Jacobijn Gussekloo et.al. in a prospective, observational, population-based, follow-up 
study in an elderly population found plasma levels of FT4 and TSH were not associated with cognitive impairment. ${ }^{[19]}$ Also, Frank Jan de Jong et.al reported that higher total and free thyroxine (T4) levels were associated with an increased risk of dementia however no associations were found for thyrotropin (TSH) ${ }^{[20]}$ We found similar results in the present study, though most of the studies mentioned above included the elderly population, while the present one included a younger population.

In the present study, the MMSE scores among patients belonging to different patterns of abnormal thyroid function were found to have been comparable, indicating the absence of any correlation between thyroid dysfunction and cognitive functioning. Ajay K. Parsaik, et $\mathrm{al}^{[14]}$ in a population-based cohort study of elderly people reported that neither clinical nor subclinical hypothyroidism was associated with minimal cognitive impairment. The present study had similar results, however, with a younger study population and being a hospital-based study. Some studies did show positive correlations between cognitive impairment and thyroid dysfunction. Yudiarto FL et.al., reported a significant decrease in attention, concentration, verbal memory, and executive function in 12 patients with overt hyperthyroidism. ${ }^{[6]}$ Graziano Ceresini et.al., in a large community-based crosssectional study in Italian patients, reported that subclinical hyperthyroidism had a lower MMSE score than euthyroid subjects. ${ }^{[5]}$ A recent Indian study by Laxmi Rajesh et. al., reported hypothyroid patients showed significantly lower MMSE scores. ${ }^{[15]}$

Discrepancies between the results of the present study and those referenced could be attributed to the distribution of thyroid abnormality among the 100 patients, which as mentioned above largely consisted of patients of overt hypothyroidism, thus providing inadequate opportunity to explore cognitive function in patients with other thyroid function abnormalities, especially subclinical hyperthyroidism for which no patients were available. A larger sample size or a sample of patients well distributed into each thyroid function abnormality may have provided more reliable results. Another reason for the discrepancies could be different age distribution as the cognitive function is primarily associated with older age groups and that the people involved in the present study were that of the working population (between ages 15 and 64), a relatively younger age group. Most studies discussed above dealt with elderly study populations. Discrepancies between the present and referenced studies can also be accounted for as variations in the nature and setting of the different studies. Besides, there might be some pitfalls in conducting an MMSE owing to its subjectivity and its relative difficulty to implement for persons speaking different languages and that the scores may also be influenced by the level of education in a person.

\section{CONCLUSION:}

In the present study, it was found that there was no association between cognitive function and abnormal thyroid function. However, owing to the shortcomings in terms of sample size, study design, and duration of the study, treatment status, etc. as discussed, further follow-up studies with a large sample size on treatment naive patients are required to study cognitive function in patients with abnormal thyroid function.

Acknowledgments: This study was done as part of the ShortTerm Studentship program of the Indian Council of Medical Research (ICMR-STS)

\section{REFERENCES:}

1. Cheng SY, Leonard JL, Davis PJ. Molecular aspects of thyroid hormone actions. Endocr Rev.2010;31(2):139-170

2. Cullen B, O'Neil B, Evans JJ, Coen RF, Lawlor BA. A review of screening tests for cognitive impairments. J Neurol Neurosur Ps 2007;78:790-79
3. Lowenstein DH, Martin JB, Hauser SL. Harrison's textbook of internal medicine. 19th ed. Mc Graw Hill education. USA, 2015. ch 437, Approach to the Patient with Neurologic Disease, p. 2535-2539

4. Begin ME, Langlois MF, Lorrain D, Cunnane SC. Thyroid function and recognition during aging. Current Gerontology and Geriatric Research. 2008;2008:1-11

5. Ceresini G, Lauretani F, Maggio M, Ceda GF, Morganti S, Usberti E et.al. Thyroid function abnormalities and cognitive impairment in elderly people: result of the Invecchiare in Chianti study. J Am Geriatr Soc.2009;57(1):89-93

6. Yudiarto FL, Muliadi L, Moeljanto D, Hartono B. Neuropsychological findings in hyperthyroid patients. Acta Med Indones- Indones J Intern Med 2006 91(7):6-10

7. de Jong FJ, Heifer T, Viser TJ, de Rijke YB, Drexhage HA, Hofman A et.al. Thyroid hormones, dementia, and atrophy of the medial temporal lobe. J Clin Endocrinol Metab 2006,91(7):2569-2573

8. Forti P, Olivelli V, Rietti E, Maltoni B, Pivazzoli G, Galti R. Serum thyroid stimulating hormone as a predictor of cognitive impairment in an elderly cohort, Gerontology.2012,55(1):41-49

9. Annerbo S, Kivipelto M, Lokk J. A prospective study on the development of Alzheimer's disease with regard to thyroid stimulating hormone and homocysteiene. Dement Geriatr Cogn Disord. 2009;28:275-280

10. Hu Y, Wang Z, Guo Q, Cheng W, Chen Y. Is thyroid status associated with cognitive impairment in elderly patients in China?. BMC Endocrine disorders. 2016;16(1):7pages

11. Allahyari T, Rangi NH, Khalkhali H, Khosravi Y. Occupational cognitive failure and safety performance in the workplace. Int J Occup Saf Ergon. 2014;20(1):175-180

12. Wu Y, Pei Y, Wang F, Xu D, Cui W. Higher FT4 or TSH below the normal range are associated with increased risk of dementia: a meta-analysis of 11 studies. Scientific reports [internet]. 2016 [cited 2020 May 30];6(1), available from: nature.com/scientific reports,DOI:10.1038/srep31975

13. Wu T, Flowers JW, Tudiver F, Wilson JL, Punyasavatsut N. Subclinical thyroid disorders and cognitive performance among adolescents in the United States. BMC Paediatrics[internet].2006 [cited 2020 May 30];6(1),6 pages,available from: bmcpediatr. biomedcentral. com/articles/ 10.1186/ 11471-2431-6-12

14. Parsaik AK, Singh B, Roberts RO, Pankratz S, Edwards KK, Gida YE et.al Hypothyroidism and risk of mild cognitive impairment in elderly persons: a population based study. JAMA Neurology.2014;71(2):201-207

15. Rajesh LCH, Endreddy AR, Shaik S, Subram S. A study of cognitive dysfunctions in patients with thyroid disorders. International Journal of Medical Research and Review.2017;5(11):933-942

16. Parle J, Roberts L, Wilson S, Patteson H, Roalfe A, Haque MS. A randomized control trial of the effect of thyroxine replacement on cognitive function in community living elderly subjects with subclinical hypothyroidism: the Birmingham elderly thyroid study. J Clin Endocrinol Metab. 2010;95(8):36233632

17. Dange NS, Thakur AS, Viplav P, Ravikant S, Girishkumar K. Spectrum of thyroid dysfunction in Bastar, Chhattisgarh: a hospital based study. T Cont Med A Dent.2015;3(3)

18. Miller KJ, Parsons TD, Whybrow PC, Herle KV, Ragson N et.al. Memory improvement with treatment of hypothyroidism. Int J Neurosci. 2006;116 (8): 895-906

19. Gussekloo J, Exel E, Craen AJM, Meinders AE, Frolich M, Westendorp RGJ. Thyroid status, disability, and cognitive function, and survival in old age. JAMA 2004·292(21):259l-2599

20. de Jong FJ, Masaki K, Chen H, Remalay AT, Breteler MMB, Petrovich H. Thyroid function, the risk of dementia and neuropathologic changes: the HonoluluAsia aging study. Neurobiol Aging. 2009;30(2009):600-606 